\title{
Spotlight on carers
}

\author{
Jones, Carys
}

\section{International Psychogeriatrics}

\author{
DOI: \\ https://doi.org/10.1017/S104161022100048X
}

Published: 01/09/2022

Peer reviewed version

Cyswllt i'r cyhoeddiad / Link to publication

Dyfyniad o'r fersiwn a gyhoeddwyd / Citation for published version (APA):

Jones, C. (2022). Spotlight on carers. International Psychogeriatrics, 34(9), 775-777. https://doi.org/10.1017/S104161022100048X

\footnotetext{
Hawliau Cyffredinol / General rights

Copyright and moral rights for the publications made accessible in the public portal are retained by the authors and/or other copyright owners and it is a condition of accessing publications that users recognise and abide by the legal requirements associated with these rights.

- Users may download and print one copy of any publication from the public portal for the purpose of private study or research.

- You may not further distribute the material or use it for any profit-making activity or commercial gain

- You may freely distribute the URL identifying the publication in the public portal ?
}

Take down policy

If you believe that this document breaches copyright please contact us providing details, and we will remove access to the work immediately and investigate your claim. 


\section{Spotlight on carers:}

\section{Commentary on: Economic evaluations of interventions for supporting adult carers in the UK: a systematic review from the NICE Guideline}

There are over 6.5 million informal carers providing support to family and friends in the UK (Buckner \& Yeandle, 2015). Older adults are the main recipient of informal care, and care is often provided by spouses who are themselves older. Informal care can include assistance with household activities such as cooking or shopping; personal care such as helping a person to wash and dress themselves; or support with organizational tasks such as transporting the person being cared for to their medical appointments or reminding them when to take medication. Inflated to 2021 prices, informal care is estimated to save the economy over £152 billion per year in avoided hours of paid homecare services (Buckner \& Yeandle, 2015). The presence of an informal carer can be a key factor in enabling a person with care needs to remain living at home, through the mechanism of delaying or avoiding the need for admission to residential care (Carers UK, 2016). However, the impact of caring on the physical and mental wellbeing of the carer can be considerable, with a survey finding that 7 out of 10 carers reported poorer mental health and 6 out of 10 reported worsened physical health as a result of caring (Carers UK, 2017).

Due to the considerable economic and societal impact of caring, it is essential that interventions are developed to support carers. In addition to evidence on the effectiveness of these interventions, evidence is needed on their cost-effectiveness. Cost-effectiveness analysis (CEA) is a popular form of economic evaluation, recommended by NICE in their guides to technology appraisal (National Institute for Health and Care Excellence, 2013) and public health evaluations (National Institute for Health and Care Excellence, 2012b). CEA uses an incremental cost-effectiveness ratio (ICER) to represent the difference in costs between alternatives under consideration (typically an intervention compared to a control condition), divided by the difference in outcomes achieved between conditions. This gives decision-makers the information needed to assess which interventions provide the best value for money and guides them in the allocation of resources.

This issue contains a systematic review by Pelone and colleagues to identify and investigate economic evidence for interventions aimed at supporting adult carers in the UK (Pelone et al., 2021). Pelone et al. begin by outlining concerns about the generalisability of economic evaluations, including differences in costs of resource use and geographical transferability between jurisdictions. As such, an aim of their review was to critically appraise the quality of economic evidence for interventions to support carers and their applicability to the UK context. Studies published in or after 2003 were eligible for inclusion, and study type could include cost-effectiveness analysis, cost-utility analysis, cost-benefit analysis, costconsequence analysis, cost-minimisation analysis and comparative cost-analysis. A broad range of intervention types were eligible for inclusion, from carer assessments to psychological support interventions. In line with concerns about the generalisability of findings in diverse geographical contexts, studies that took place in the US were excluded due to the substantial differences in healthcare models between the UK and US. The applicability and methodological quality of included studies was assessed using a checklist for economic evaluations developed by NICE (National Institute for Health and Care Excellence, 2012a).

From the initial 15,657 articles identified through the searches, 61 remained after removal of duplicates and screening of title and abstracts. Full-text articles were retrieved and assessed, leading to a further 51 being excluded for lack of study design $(n=20)$, no population of interest (14), not being applicable to the guideline decision context $(n=8)$, containing no relevant intervention $(n=6)$, or other reason $(n=3)$. This left only 10 articles of interest for the review. Five of these studies contained economic evaluations of interventions 
for carers of people living with dementia, two were for carers of people with cancer, two were for carers of people who had experienced a stroke, and one was for carers of people at the end of life. Interestingly, the spread of condition type in the included studies is not representative of the general landscape for research funding, as cancer research typically receives twice as much funding per person with the condition as dementia does and five times as much funding per person as stroke research (Luengo-Fernandez et al., 2015).

Six of the studies were conducted in the UK, two in Australia, one in the Netherlands, and one in Canada. Publication years ranged from 2004 to 2019, and costs were presented in the original price year and currency of the country of origin. The most frequent type of economic evaluation was cost-utility analysis with nine of the included articles using it; the remaining study used cost-analysis. Cost-utility analysis is a form of CEA where the unit of measurement is the Quality-adjusted Life Year (QALY), which combines health-related quality of life with length of time. Whilst a benefit of cost-utility analysis is the reporting of outcomes in a common metric, thus enabling comparisons across different conditions, one must consider whether a QALY is an appropriate conceptual basis to measure quality of life outcomes in interventions tailored at carers. As Pelone et al. note, economic evaluations of psychosocial/ social care interventions may have broader aims than improving the healthrelated quality of life of carers, thus different outcome measures should be considered. Often, it is appropriate to include a secondary measure of quality of life such as the impact on carer stress or strain, care-related quality of life, or capability.

Over half of the studies in this review had a time horizon of under one year. NICE guidance advises that the time horizon for an evaluation should incorporate all important costs and effects relating to an intervention. However, few research studies have sufficient funding to enable a long-term follow-up of participants so pragmatically it is not surprising to see the shorter time horizons in these included studies. The perspective chosen for an evaluation will influence how costs and outcomes borne by carers are included in the analyses. In the NICE reference case for technology appraisal all direct health effects are included, but only NHS and personal social service (PSS) costs should be considered. In contrast, the NICE public health guidance suggests using a broader perspective which includes lost productivity and any costs that are not reimbursed by the public sector. The studies included in this review adopted a range of perspectives (4 health and social care, 3 health care, 2 societal, 1 public sector), but the extent to which those claiming a societal perspective truly incorporated opportunity costs for carers was unclear.

The review helpfully presents a narrative synthesis of findings by intervention type: psychological and emotional support; support for carers during changes to their caring role; social support interventions; and end of life support. Psychological and emotional support interventions were conducted in five studies. Three of the interventions were found to be cost-effective compared to the comparator condition (a manual based coping strategy intervention; a cognitive-behavioural intervention via telephone; and an intensive care management model). One cost-analysis study was found to yield cost savings for carers after receiving the intervention (group-based cognitive behavioural therapy with an uncontrolled pre-post study design). Group reminiscence therapy with both the carer and person being cared for was found to be dominated by the control condition (i.e. the control condition was more effective and lower cost). Of the interventions for supporting carers during changes to their caring role, one was found to be cost-effective (training carers in basic nursing and facilitation of personal care for people post-stroke), whilst one was not cost-effective (structured training programme for carers of people post-stroke). Neither of the two social support interventions were found to be cost-effective (befriending by a volunteer; and a pro-active telephone information and support service compared to a reminder only telephone service). The sole end of life support study was a multi-arm trial of family conference between an intensive care unit and carers of people at the end of life, nurse-led psychological educational training, a multifaceted support intervention, and treatment as usual. None of the intervention conditions were found to be cost-effective. 
A quality assessment of the included studies deemed all to be 'partially applicable' to the context of NICE guidelines for supporting adult carers in the UK. However, Pelone et al. found a variation in the methodological quality of included studies. Four of the ten studies were assessed as having potentially serious methodological limitations and one as having very serious limitations. The main methodological limitations were in reporting of the time horizon, providing estimates of relative intervention effects (i.e. production of an ICER in cost-effectiveness analyses), and the inclusion of appropriate sensitivity analyses. The authors of the review present four potential limitations of the review. Firstly, the restriction of included studies to those published in English, although this is a minor limitation given that the aim of the review was to identify evidence relevant to a UK context. Secondly, the limited and heterogeneous nature of included studies could have been correlated to search and selection bias; however, this is unlikely as the research was reviewed and overseen by the NICE Guideline Committee. Thirdly, reviewers were not blind to the authors of the included studies. Finally, the search date was limited to studies published in or after 2003 which could have led to the exclusion of earlier, relevant studies. The authors justify the publication year limit as being linked to the introduction of the Carers (Equal Opportunities) Act 2004.

Despite the volume of evidence into the effectiveness of interventions to support carers (National Institute for Health and Care Excellence, 2020), this review clearly demonstrates the lack of accompanying economic evidence. What little evidence is available, is varying in methodological quality. The authors identify research gaps in economic evidence and call for future research to target interventions for identifying carers, strategies for assessing their needs, and programmes for providing carers with support and advice to help them enter, remain in, or return to work or education. Additionally, the methodological quality of evaluations should be strengthened through adopting a societal perspective and a time horizon long enough to capture the costs and outcomes of an intervention. The production of high-quality economic evidence into interventions to support carers is essential to inform decision-making about resource allocation.

\section{Conflict of interest}

None.

Carys Jones

Centre for Health Economics and Medicines Evaluation, Bangor University, UK

Email: c.l.jones@bangor.ac.uk

\section{References}

Buckner, L., \& Yeandle, S. (2015). Valuing Carers 2015: the rising value of carer's support.

Carers UK. (2016). Pressure points: carers and the NHS.

Carers UK. (2017). State of Caring 2017.

Luengo-Fernandez, R., Leal, J., \& Gray, A. (2015). UK research spend in 2008 and 2012: Comparing stroke, cancer, coronary heart disease and dementia. BMJ Open, 5(4). https://doi.org/10.1136/bmjopen-2014-006648

National Institute for Health and Care Excellence. (2012a). Appendix G: Methodology checklist: economic evaluations. In Developing NICE guidelines: the manual. https://www.nice.org.uk/process/pmg6/resources/the-guidelines-manual-appendices-bi- 
2549703709/chapter/appendix-g-methodology-checklist-economic-evaluations

National Institute for Health and Care Excellence. (2012b). Methods for the development of NICE public health guidance (third edition). In National Institute of Health and Care Excellence (Issue September).

https://www.nice.org.uk/process/pmg4/resources/methods-for-the-development-of-nicepublic-health-guidance-third-edition-pdf-2007967445701

National Institute for Health and Care Excellence. (2013). Guide to the methods of technology appraisal. https://doi.org/10.2165/00019053-200826090-00002

National Institute for Health and Care Excellence. (2020). Supporting adult carers. https://www.nice.org.uk/guidance/ng150

Pelone, F., Jacklin, P., Francis, J., \& Purchase, B. (2021). Economic evaluations of interventions for supporting adult carers in the UK: a systematic review from the NICE Guideline. International Psychogeriatrics. 